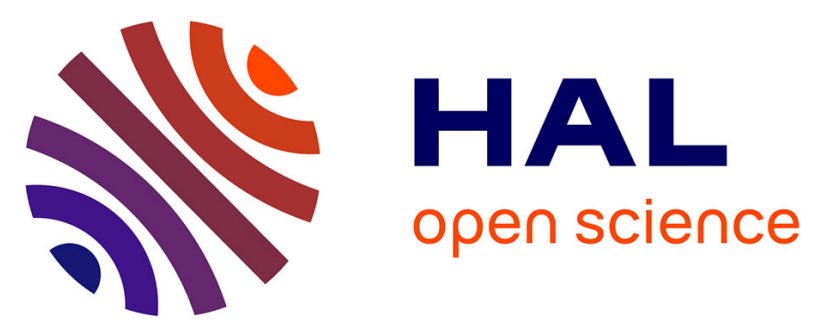

\title{
Nutrient limitation, bioenergetics and stoichiometry: A new model to predict elemental fluxes mediated by fishes
}

Nina M D Schiettekatte, Diego R Barneche, Sébastien Villéger, Jacob E Allgeier, Deron E Burkepile, Simon J Brandl, Jordan M Casey, Alexandre Mercière, Katrina S Munsterman, Fabien Morat, et al.

\section{To cite this version:}

Nina M D Schiettekatte, Diego R Barneche, Sébastien Villéger, Jacob E Allgeier, Deron E Burkepile, et al.. Nutrient limitation, bioenergetics and stoichiometry: A new model to predict elemental fluxes mediated by fishes. Functional Ecology, 2020, 34 (9), pp.1857-1869. 10.1111/1365-2435.13618 . hal03013820

\section{HAL Id: hal-03013820 \\ https:/ /hal-univ-perp.archives-ouvertes.fr/hal-03013820}

Submitted on 24 Nov 2021

HAL is a multi-disciplinary open access archive for the deposit and dissemination of scientific research documents, whether they are published or not. The documents may come from teaching and research institutions in France or abroad, or from public or private research centers.
L'archive ouverte pluridisciplinaire HAL, est destinée au dépôt et à la diffusion de documents scientifiques de niveau recherche, publiés ou non, émanant des établissements d'enseignement et de recherche français ou étrangers, des laboratoires publics ou privés. 
3 Nina M. D. Schiettekatte ${ }^{1,2, *}$, Diego R. Barneche ${ }^{3}$, Sébastien Villéger ${ }^{4}$, Jacob E. Allgeier ${ }^{5}$, 4 Deron E. Burkepile ${ }^{6,7}$, Simon J. Brandl ${ }^{8}$, Jordan M. Casey ${ }^{1,2}$, Alexandre Mercière ${ }^{1,2}$, Katrina 5 S. Munsterman ${ }^{5}$, Fabien Morat ${ }^{2}$, Valeriano Parravicini ${ }^{1,2}$

$6{ }^{1}$ PSL Université Paris: EPHE-UPVD-CNRS, USR 3278 CRIOBE, Université de Perpignan, 66860 Perpignan, 7 France

$8 \quad 2$ Laboratoire d'Excellence "CORAIL," Perpignan, France

$9{ }^{3}$ Australian Institute of Marine Science, Crawley, WA 6009, Australia

${ }_{10}{ }^{4}$ Université Montpellier, CNRS, IFREMER, IRD, 34095 Montpellier, France

${ }_{1}^{5}$ Department of Ecology and Evolutionary Biology, University of Michigan, Ann Arbor, Michigan 48109, USA

$12{ }^{6}$ Department of Ecology, Evolution, and Marine Biology, University of California, Santa Barbara, Santa Barbara, CA, United States

${ }^{7}$ Marine Science Institute, University of California, Santa Barbara, Santa Barbara, CA, United States

${ }^{8}$ Department of Biological Sciences, Simon Fraser University, Burnaby, BC V5A 1S6, Canada

Correspondence to: N.M.D.S.; Email: nina.schiettekatte@gmail.com

Running title: Modelling elemental fluxes in fishes

Key-words: nitrogen, phosphorus, bioenergetics, nutrient cycling, fish, stoichiometry, ingestion, excretion, nutrient limitation

\section{Acknowledgements}

We thank the staff at CRIOBE, Moorea for field support. We would also like to thank Benoit Espiau, Calvin Quigley, Kaitlyn Landfield and Tommy Norin for their help in the field, and Guillemette de Sinéty and Jérémy Wicquart for their contribution to otolith analyis. This work was supported by the BNP Paribas Foundation as a part of the ReefServices project, the Agence National de la Recherche (REEFLUX, ANR-17-CE32-0006) and the U.S. National Science Foundation (OCE-1547952). Finally, we thank two anonymous reviewers, whose comments substantially improved this manuscript. 
28 Author contributions

29 NMDS conceived the idea and NMDS, VP, DRB and SV designed methodology; NMDS,

30 JMC, SJB, AM, FM, VP, KSM, JEA and DEB collected the data; NMDS analysed the data

31 and led the writing of the manuscript. All authors contributed significantly to the drafts and 32 approved the final version for publication. 
1 Nutrient limitation, bioenergetics, and stoichiometry predict elemental fluxes mediated 2 by fishes

\section{Abstract}

4 1. Energy flow and nutrient cycling dictate the functional role of organisms in ecosystems.

5 Fishes are key vectors of carbon $(\mathrm{C})$, nitrogen $(\mathrm{N})$, and phosphorus $(\mathrm{P})$ in aquatic systems, and 6 the quantification of elemental fluxes is often achieved by coupling bioenergetics and stoi7 chiometry. While nutrient limitation has been accounted for in several stoichiometric models, 8 there is no current implementation that permits its incorporation into a bioenergetics approach 9 to predict consumption rates. This may lead to biased estimates of elemental fluxes.

10 2. Here, we introduce a theoretical framework that combines stoichiometry and bioenergetics with explicit consideration of limitation. We examine varying elemental limitations across different trophic groups and life stages through a case study of three trophically-distinct reef fishes. Further, we empirically validate our model using an independent database of measured excretion rates.

3. Our model adequately predicts elemental fluxes in the examined species and reveals species- and size-specific limitations of $\mathrm{C}, \mathrm{N}$, and P. In line with theoretical predictions, we demonstrate that the herbivore Zebrasoma scopas is limited by $\mathrm{N}$ and $\mathrm{P}$, and all three fish species are limited by $\mathrm{P}$ in early life stages. Further, we show that failing to account for nutrient limitation can result in a greater than two-fold underestimation of ingestion rates, which leads to drastic underestimations of excretion rates.

4. Our model improved predictions of ingestion, excretion, and egestion rates across all life stages, especially for fishes with diets low in $\mathrm{N}$ and/or P. Due to its broad applicability, its reliance on many parameters that are well defined and widely accessible, and its straightforward implementation via the accompanying R-package $f$ ishflux, our model provides a userfriendly path toward a better understanding of ecosystem-wide nutrient cycling in the aquatic biome. 


\section{Introduction}

Internal biological processes of consumer species, such as growth, respiration, and excretion are important drivers of ecosystem-scale biogeochemical cycles (Welti et al., 2017). To survive, individuals need to gather resources from the environment and, in doing so, transfer energy and nutrients within and across ecosystems (Brown, Gillooly, Allen, Savage, \& West, 2004; Mackenzie, Ver, Sabine, Lane, \& Lerman, 1993). Therefore, the quantification of energy and nutrient fluxes in ecosystems hinges on our ability to understand how energy and materials are utilized and transformed at the individual level (Allgeier, Yeager, \& Layman, 2013; Kitchell et al., 1974; Sterner \& Elser, 2002).

In aquatic ecosystems, fishes account for most of the heterotrophic biomass (Odum \& Odum, 1955; Vanni, 2002) and contribute substantially to the storage and flux of carbon (C), nitrogen (N), and phosphorus P (Allgeier, Layman, Mumby, \& Rosemond, 2014; Barneche et al., 2014; Burkepile et al., 2013; McIntyre et al., 2008; Vanni, 2002). Storage is primarily dictated by food that is assimilated and allocated to growth, which ultimately underpins critical ecosystem services (e.g. finfish fisheries). Fluxes are derived from assimilated (respired carbon and excreted nutrients) and non-assimilated food (egested organic waste) (Schreck \& Moyle, 1990), and they can have important effects on ecosystem processes, such as primary production (Allgeier et al., 2013; Capps \& Flecker, 2013; McIntyre et al., 2008). Disentangling how fishes partition ingested elements into biomass and waste products is therefore key to link individual-level physiology to ecosystem-level processes, which are of inherent human interest (Anderson, Hessen, Elser, \& Urabe, 2005; Barneche \& Allen, 2018; Hessen, Ågren, Anderson, Elser, \& De Ruiter, 2004; Hou et al., 2008).

Ecological stoichiometry provides a theoretical framework to understand how consumers partition C, N, and P (Sterner \& Elser 2002). On the basis of the conservation of mass, the material ingested by consumers equals the sum of biomass accumulation and waste products such as respired carbon, excreted nutrients, and egested organic material. Furthermore, stoichiometric theory predicts that the ratio of recycled elements depends on the elemental composition of the consumer body, diet, and the gross growth efficiency of the limiting element (Frost 
et al., 2006; Sterner, 1990). Thus, given known consumption rates, stoichiometric mass balance models allow for the prediction of fish excretion rates (Kraft, 1992; Schindler \& Eby, 1997). Consumption rates can be approximated using empirical relationships with body mass and temperature (e.g. El-Sabaawi, Warbanski, Rudman, Hovel, \& Matthews, 2016), but these estimates are highly species-specific, require extensive lab experiments, and may not reflect fish consumption rates in the wild.

Alternatively, consumption rates can be estimated using bioenergetic models. In fact, there is a rich history of bioenergetic modelling approaches to estimate energy allocation in fishes under the assumption that they are limited by energy (C) (e.g. the "Wisconsin model", Kitchell et al. (1974); Hanson, Johnson, Schindler, \& Kitchell (1997) and the "Dynamic Energy Budget model", Kooijman (2010)). Combined with elemental stoichiometry, bioenergetic models therefore provide a conceptual basis to predict how fishes partition energy and elements into growth, metabolism, and waste (Deslauriers, Chipps, Breck, Rice, \& Madenjian, 2017; Kraft, 1992; Schindler \& Eby, 1997; Schreck \& Moyle, 1990). This approach has been widely used to estimate consumption rates, given known growth rates in wild fish populations (especially via the Fish Bioenergetics software Deslauriers et al., 2017). Nutrient cycling predictions are then made by combining modeled ingestion rates based on energetic needs, assimilation efficiencies, and nutrient stoichiometry of both a fish's body and diet (Anderson et al., 2005; Kraft, 1992; Schindler \& Eby, 1997).

Although useful and successfully implemented (Deslauriers et al., 2017), this approach is limited in its application to fishes that are limited by $\mathrm{C}$. This can be the case, especially for trophic groups that feed on nutrient-rich prey (e.g. Schindler \& Eby, 1997); yet, many fish species in low trophic levels may be limited by $\mathrm{N}$ or $\mathrm{P}$ because their diets contain lower nutrient levels than their body tissues (McIntyre et al., 2008; Schindler \& Eby, 1997). Thus, applying the traditional approach of combining stoichiometry and bioenergetics (Kraft, 1992) to fish species that are limited by $\mathrm{N}$ or $\mathrm{P}$ normally results in biologically impossible predictions of negative excretion rates. Indeed, there is mounting evidence that fishes can be limited by nutrients, rather than energy (Benstead et al., 2014; El-Sabaawi et al., 2016; Hood2005; Moody, Lujan, Roach, \& Winemiller, 2019). While, negative predicted excretion rates can 
provide evidence for nutrient limitation (e.g. Hood, Vanni, \& Flecker, 2005), they do not aid our understanding and prediction of realistic elemental fluxes in communities where nutrientlimited species are prevalent. Thus, although many stoichiometric models take into account nutrient limitation (e.g. Sterner, 1990; El-Sabaawi et al., 2016; Guariento, Luttbeg, Carneiro, \& Caliman, 2018; Moody et al., 2018, 2019), there is presently no solution for integrating nutrient limitation into bioenergetic models that quantify consumption rates. As fishes in low trophic levels often account for a significant proportion of biomass (e.g. Graham et al., 2017) and represent important vectors of nutrients, a new approach is needed to accurately predict elemental fluxes in the absence of known consumption rates.

Here, we present a theoretical framework (and a companion R package for its implementation: fishflux) to predict elemental fluxes in fishes that combines bioenergetics and ecological stoichiometry while directly accounting for $\mathrm{N}$ and $\mathrm{P}$ limitation, alongside $\mathrm{C}$ limitation. The proposed model framework predicts ingestion rates based on the needs of a fish at a certain size for all three elements and a known growth rate. We test our framework via a case study of three trophically-distinct coral reef fish species: the herbivore Zebrasoma scopas (family Acanthuridae), the omnivore Balistapus undulatus (family Balistidae), and the carnivore Epinephelus merra (family Serranidae). We also validate our model against independent empirical excretion estimates for our three fish species. Furthermore, we test whether fishes in different trophic levels and life stages are limited by different elements and hypothesize that fishes at low trophic levels are limited by $\mathrm{N}$ or $\mathrm{P}$ rather than $\mathrm{C}$. Finally, we posit that, by building on existing approaches, our framework considerately improves the prediction of key processes such as ingestion and excretion in the case of strong nutrient limitation, as compared to models that only consider C-limitation. 


\section{Materials and Methods}

\section{Theoretical framework}

Carbon, nitrogen, and phosphorus (CNP, expressed in grams) are the three chemical elements considered in our model. The approach applies a mass-balance framework based on ecological stoichiometry and the metabolic theory of ecology (Brown et al., 2004; Sterner \& Elser, 2002). Further, the approach relies on the growth trajectory of natural fish populations. The proposed model has four main steps (Fig. 1): (1) The minimal required ingestion or minimal supply rate of CNP is defined as the sum of CNP needed for a given growth increment and minimal inorganic flux (i.e. the minimal requirements of CNP needed for metabolism and the maintenance of the body stoichiometry). In this step, we also consider assimilation efficiency, which is defined as the capacity of an organism to assimilate $\mathrm{C}, \mathrm{N}$ or $\mathrm{P}$ (input parameters of the model). (2) Ingestion is estimated based on the limiting element that is defined by the imbalance between the CNP composition of the minimal supply rate and that of the diet. (3) The egestion rate is then quantified according to the ingestion rate and the assimilation efficiencies of each element. (4) The residual CNP are allocated toward the total inorganic flux of CNP (i.e. the waste inorganic CNP that is produced from physiological transformation). For the sake of comparison with existing literature, we note that the inorganic flux of $\mathrm{C}$ is generally called total metabolic rate, whereas the inorganic fluxes of $\mathrm{N}$ and $\mathrm{P}$ are called excretion rates. Materials that are not assimilated are egested as organic waste. An overview of all main variables predicted by the model and input parameters that need to be specified by the user is given in Table 1, while other parameters mentioned in the text are fixed in the model. In the following sections, we detail each component of the model. 


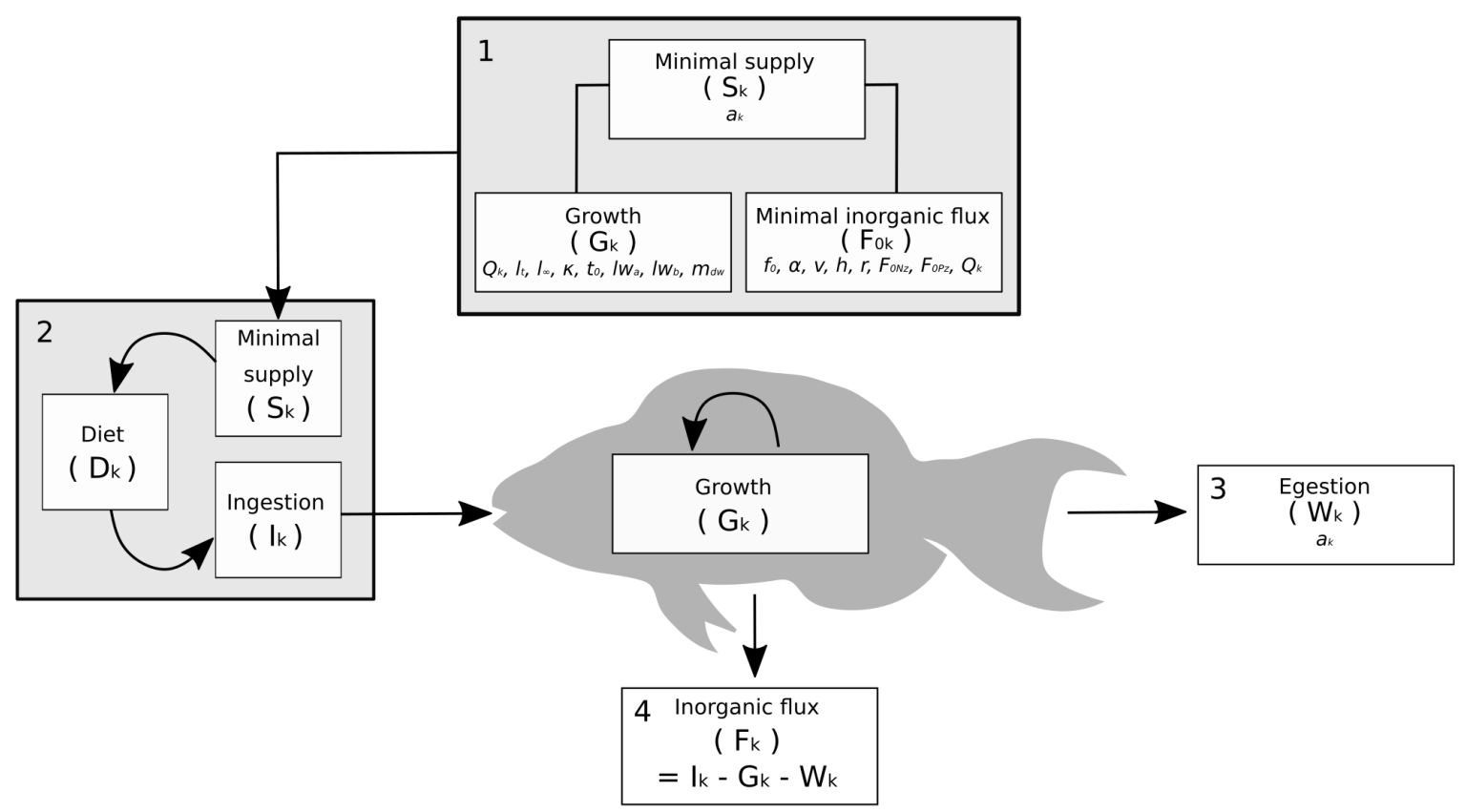

Figure 1. Conceptual diagram, explaining different model components. Required ingestion of $\mathrm{C}, \mathrm{N}$ and $\mathrm{P}$ is calculated through the sum of elements needed for growth and minimal inorganic flux, taking into account the element-specific assimilation efficiencies, $a_{\mathrm{k}}(1)$. Based on the limiting element (due to the imbalance of food and the required CNP), the ingestion rate can be estimated (2). The ingested material is partitioned into egestion (3) and assimilation (body mass growth and flux (4)). The symbol of each component is indicated in between brackets. The input parameters needed to calculate the different variables are italicised. See Table 1 for a description of each parameter. 
Table 1. Overview of model parameters and variables, including input parameters, to be specified by the user of the model, which are indicated with $*$. Main output variables, predicted by the model are indicated with $\mathbf{\Delta}$. VBGC $=$ von Bertalanffy growth curve.

\begin{tabular}{|c|c|c|}
\hline Symbol & Description & Unit \\
\hline$k$ & Index for element $\mathrm{C}, \mathrm{N}$ or $\mathrm{P}$ & - \\
\hline$S_{\mathrm{k}} \boldsymbol{\Delta}$ & Element-specific minimal supply rate & $\mathrm{g} \mathrm{d}^{-1}$ \\
\hline$G_{\mathrm{k}} \boldsymbol{\Delta}$ & Element-specific growth & $\mathrm{g} \mathrm{d}^{-1}$ \\
\hline$F_{0 \mathrm{k}} \Delta$ & Element-specific minimal inorganic flux & $\mathrm{g} \mathrm{d}^{-1}$ \\
\hline$a_{\mathrm{k}} *$ & Element-specific assimilation efficiency & - \\
\hline$l_{\mathrm{t}} *$ & Total length of individual at time $t$ & $\overline{\mathrm{cm}}$ \\
\hline$t$ & Age & yr \\
\hline$l_{\infty} *$ & Asymptotic adult length (VBGC) & $\mathrm{cm}$ \\
\hline$\kappa *$ & Growth rate parameter (VBGC) & $\mathrm{yr}^{-1}$ \\
\hline$t_{0}$ * & Age at settlement (VBGC) & yr \\
\hline$l w_{a}$ * & Parameter length-weight relationship & $\mathrm{g} \mathrm{cm}^{-1}$ \\
\hline$l w_{b} *$ & Parameter length-weight relationship & - \\
\hline$Q_{\mathrm{k}} *$ & Element-specific body content percentage of dry mass & $\%$ \\
\hline$m_{\mathrm{W}}$ & Wet body mass & $\mathrm{g}$ \\
\hline$F_{0 \mathrm{Cr}}$ & Resting metabolic rate & $\mathrm{g} \mathrm{d}^{-1}$ \\
\hline$F_{0 \mathrm{Cz}}$ & Mass-specific turnover rate of $\mathrm{C}$ & $\mathrm{g} \mathrm{Cg}^{-1} \mathrm{~d}^{-1}$ \\
\hline$F_{0 \mathrm{Cs}}$ & Rate of $\mathrm{C}$ spent in body mass growth & $\mathrm{g} \mathrm{d}^{-1}$ \\
\hline$f_{0}$ * & Metabolic normalisation constant independent of body mass & $\mathrm{g} \mathrm{Cg}^{-\alpha} \mathrm{d}^{-1}$ \\
\hline$\alpha$ 米 & Mass-scaling exponent & - \\
\hline$m_{w \infty}$ & Asymptotic wet mass of an adult individual & $\mathrm{g}$ \\
\hline$\phi$ & Cost of growth & $\mathrm{g} \mathrm{C} \mathrm{g}^{-1}$ \\
\hline$\theta$ 米 & Activity scope & \\
\hline$v *$ & Environmental temperature & ${ }^{\circ} \mathrm{C}$ \\
\hline$h$ * & trophic level & - \\
\hline$r$ * & Aspect ratio of caudal fin & - \\
\hline$F_{0 \mathrm{Nz}}$ * & Mass-specific turnover rate of $\mathrm{N}$ & $\mathrm{g} \mathrm{Ng}^{-1} \mathrm{~d}^{-1}$ \\
\hline$F_{0 \mathrm{Pz}}$ 米 & Mass-specific turnover rate of $\mathrm{P}$ & $\mathrm{g} \mathrm{Pg}^{-1} \mathrm{~d}^{-1}$ \\
\hline$m_{\mathrm{dw}}$ & Ratio of dry mass and wet mass of fish & - \\
\hline$m_{\mathrm{d}}$ & Dry body mass & $\mathrm{g}$ \\
\hline$D_{\mathrm{k}} *$ & Element-specific diet content percentage of dry mass & $\%$ \\
\hline$I_{\mathrm{k}} \boldsymbol{\Delta}$ & Element-specific ingestion rate & $\mathrm{g} \mathrm{d}^{-1}$ \\
\hline$W_{\mathrm{k}} \boldsymbol{\Delta}$ & Element-specific egestion rate & $\mathrm{g} \mathrm{d}^{-1}$ \\
\hline$F_{\mathrm{rk}} \boldsymbol{\Delta}$ & Element-specific residual inorganic flux & $\mathrm{g} \mathrm{d}^{-1}$ \\
\hline$F_{\mathrm{k}} \boldsymbol{\Delta}$ & Element-specific total inorganic flux & $\mathrm{g} \mathrm{d}^{-1}$ \\
\hline
\end{tabular}




\subsection{Minimal suppy rate}

The first step of the model is an estimate of the minimal supply rate of elements $(\mathrm{C}, \mathrm{N}$ and $\mathrm{P})$ required per day for a given growth increment in an individual of a given size. The required CNP is the sum of the elements needed for body mass growth and overhead metabolic and maintenance costs (i.e. minimal inorganic flux). The minimal supply rate $S_{\mathrm{k}}\left(\mathrm{g} \mathrm{d}^{-1}\right)$ of the element $\mathrm{k}=\{\mathrm{C}, \mathrm{N}, \mathrm{P}\}$ can therefore be estimated as

$$
S_{\mathrm{k}}=\frac{\left(G_{\mathrm{k}}+F_{0 \mathrm{k}}\right)}{a_{\mathrm{k}}}
$$

where $G_{\mathrm{k}}, F_{0 \mathrm{k}}$ and $a_{\mathrm{k}}$ are element-specific growth rate $\left(\mathrm{g} \mathrm{d}^{-1}\right)$, minimal inorganic flux $\left(\mathrm{g} \mathrm{d}^{-1}\right)$, and assimilation efficiency (\%), respectively.

\subsubsection{Growth}

The aim of our model is to predict elemental fluxes of fishes in their natural environment. Therefore, we use growth rates that can be calculated from otolith analysis. In our model, we thus assume that there is enough food available to fulfill the observed growth pattern. We further use the von Bertalanffy growth curve (VBGC) to describe the growth trajectory (Bertalanffy, 1957). Empirically, the VBGC is favorable because its parameters are statistically simple to obtain, easy to interpret, and are available for a large number of species (Morais \& Bellwood, 2018). Body length, $l_{t}$ (cm in total length, i.e. T.L.), at age $t(\mathrm{yr})$ is

$$
l_{t}=l_{\infty}\left(1-e^{-\kappa\left(t-t_{0}\right)}\right)
$$

where $t_{0}$ is age at settlement, $l_{\infty}$ is the asymptotic adult length (i.e. length when growth rate is 0$)$, and $\kappa$ is a growth rate parameter $\left(\mathrm{yr}^{-1}\right)$ (Bertalanffy, 1957). With this equation, we can quantify the age of a fish of a certain size. Then, by adding one day to that age, we can also approximate the amount a fish will grow in one day. Using length-weight relationships and wet-to-dry mass conversion constants from the literature and FishBase (Froese \& Pauly, 2018), we can finally calculate total growth rate (i.e. $G)$ expressed in dry mass $\left(\mathrm{g} \mathrm{d}^{-1}\right)$. Using 
element-specific body content percentages, $Q_{\mathrm{k}}$, we calculate element-specific growth as:

$$
G_{\mathrm{k}}=\frac{Q_{\mathrm{k}}}{100} G
$$

\subsubsection{Minimal inorganic flux}

Traditionally, the field metabolic rate, $F_{0 \mathrm{C}}$, has been studied more intensively than minimal excretion rates for $\mathrm{N}$ and $\mathrm{P}, F_{0 \mathrm{~N}}$, and $F_{0 \mathrm{P}}$. As a consequence, we currently have a better understanding of how assimilated carbon is partitioned into body mass growth $\left(G_{C}\right)$ and metabolic overhead costs $\left(F_{0 \mathrm{C}}\right)$. For instance, we know that $F_{0 \mathrm{C}}$ predictably scales with individual wet body mass, $m_{w}(\mathrm{~g})$ (Hou et al., 2008):

$$
\begin{array}{r}
F_{0 \mathrm{C}}=\theta F_{0 \mathrm{C} r}= \\
\theta\left(F_{0 \mathrm{C} z} m_{w}+F_{0 \mathrm{C} s}\right)= \\
\theta\left(f_{0} m_{w \infty}^{\alpha-1} m_{w}+\phi G\right),
\end{array}
$$

where $F_{0 \mathrm{Cr}}$ is the resting metabolic rate $\left(\mathrm{g} \mathrm{C} \mathrm{d}^{-1}\right), F_{0 \mathrm{C} z}$ is the mass-specific turnover rate $(\mathrm{g} \mathrm{C}$ $\left.\mathrm{g}^{-1} \mathrm{~d}^{-1}\right), F_{0 \mathrm{Cs}}$ is the rate of carbon spent in body mass growth, and $f_{0}$ is a metabolic normalization constant that is independent of body mass $\left(\mathrm{g} \mathrm{C} \mathrm{g}^{-\alpha} \mathrm{d}^{-1}\right)$ and varies among fish taxa, environmental temperature, and trophic level (Barneche \& Allen, 2018). $\alpha$ is a dimensionless mass-scaling exponent (generally between 0.5 and 1 ), $m_{w \infty}$ is the asymptotic mass of an individual, and $\phi$ is the energy expended to produce one unit of body mass ( $\mathrm{g} \mathrm{C} \mathrm{g}^{-1}$; hereafter the "cost of growth"). In equation $4, F_{0 \mathrm{C}}$ is defined as the sum of the resting metabolic rate, $F_{0 \mathrm{C} r}$, and the active rate that sustains locomotion, feeding, and other activities. We assume that $F_{0 \mathrm{C}}=\theta F_{0 \mathrm{C} r}$ in the expression above, where $\theta$ is a dimensionless parameter referred to as 'activity scope', which is constrained to be greater than 1 and less than the ratio between maximum metabolic rate and resting metabolic rate (Barneche \& Allen, 2018; Hou et al., 2008). The cost of growth, $\phi$, varies substantially among fishes, and it may increase with environ- 
mental temperature, $v$, trophic level, $h$, and aspect ratio of caudal fin, $r$ (a proxy for activity level) (Froese \& Pauly, 2018). Following Barneche \& Allen (2018), the cost of growth can be calculated as

$$
\ln \phi=\beta_{0}+\beta_{v} v+\beta_{h} \ln h+\beta_{r} \ln (r+1),
$$

where $\beta_{0}$ is a constant, $\beta_{v}, \beta_{h}$, and $\beta_{r}$ are respectively the model slopes for $v, h$, and $r$. We note that $h$ and $r$ are two ecological variables that can be retrieved from FishBase (Froese \& Pauly, 2018). For the purposes of our bioenergetic model, we use average, across-species estimates for $\beta_{0}, \beta_{v}, \beta_{h}$, and $\beta_{r}$ published in Barneche \& Allen (2018).

Aside from inorganic fluxes of $\mathrm{C}, \mathrm{N}$ and $\mathrm{P}$ will also be released at a minimal rate, even when they are limiting (Anderson et al., 2005; Sterner \& Elser, 2002). The minimal inorganic flux of $\mathrm{N}$ and $\mathrm{P}$ can be experimentally measured as minimal excretion rates during starvation (Mayor et al., 2011). We can thus explicitly incorporate $\mathrm{N}$ and $\mathrm{P}$ turnover rates to estimate minimal inorganic flux of $\mathrm{N}$ and $\mathrm{P}$ (Anderson et al., 2005).

$$
F_{0 \mathrm{~N}}=F_{0 \mathrm{~N} z} \frac{Q_{\mathrm{N}}}{100} m_{d}, \text { and }
$$

where $F_{0 \mathrm{~N} z}$ and $F_{0 \mathrm{P} z}$ are nutrient-specific dry mass-specific turnover rates for $\mathrm{N}\left(\mathrm{g} \mathrm{N} \mathrm{g}^{-1} \mathrm{~d}^{-1}\right)$ and $\mathrm{P}\left(\mathrm{g} \mathrm{P} \mathrm{g}^{-1} \mathrm{~d}^{-1}\right)$, respectively, and $m_{d}$ is the dry mass of the fish (g). Equations 6 and 7 assume that $F_{0 \mathrm{~N} z}$ and $F_{0 \mathrm{P} z}$ remain constant during ontogeny.

\subsection{Ingestion}

In our model, the quantification of ingestion rate is a two-step process. First, we define the minimal required ingestion of CNP by summing element-specific minimal supply rates $S_{\mathrm{k}}$. Second, we approximate the actual ingestion rates by using ecological stoichiometric theory (Sterner \& Elser, 2002). With known elemental stoichiometry of the $\operatorname{diet}\left(D_{\mathrm{C}}, D_{\mathrm{N}}, D_{\mathrm{P}}\right)$ we can 
determine the limiting element as follows:

$$
\text { limiting element }=\left\{\begin{array}{ll}
C, & \text { if } \frac{S_{\mathrm{C}}}{S_{\mathrm{N}}}>\frac{D_{\mathrm{C}}}{D_{\mathrm{N}}} \text { and } \frac{S_{\mathrm{C}}}{S_{\mathrm{P}}}>\frac{D_{\mathrm{C}}}{D_{\mathrm{P}}} \\
N, & \text { if } \frac{S_{\mathrm{N}}}{S_{\mathrm{P}}}>\frac{D_{\mathrm{N}}}{D_{\mathrm{P}}} \text { and } \frac{S_{\mathrm{C}}}{S_{\mathrm{N}}}<\frac{D_{\mathrm{C}}}{D_{\mathrm{N}}} \\
P, & \text { otherwise }
\end{array}\right\}
$$

7

The actual ingestion rate is then approximated according to the limiting element, following Liebig's minimum law. To do so, we assume fishes have enough food available to meet their minimal needs $\left(S_{\mathrm{k}}\right)$. For example, if $\mathrm{P}$ is limiting, element-specific ingestion rates, $I_{\mathrm{k}},\left(\mathrm{g} \mathrm{d}^{-1}\right)$ are

$$
I_{\mathrm{P}}=S_{\mathrm{P}},
$$

$$
I_{\mathrm{N}}=I_{\mathrm{P}} \frac{D_{\mathrm{N}}}{D_{\mathrm{P}}},
$$

$$
I_{\mathrm{C}}=I_{\mathrm{P}} \frac{D_{\mathrm{C}}}{D_{\mathrm{P}}},
$$

where $D_{\mathrm{k}}$ represents element-specific body content percentage of dietary items. Once ingestion rate is estimated, the partitioning of the ingested matter into various pathways (i.e. egestion, excretion and respiration) can be defined.

\subsection{Egestion or organic waste production}

The rate of organic waste production or egestion rate, $W_{\mathrm{k}}\left(\mathrm{g} \mathrm{d}^{-1}\right)$ can be computed using the ingestion rate of each element and element-specific assimilation efficiencies (Schreck \& Moyle, 1990):

$$
W_{\mathrm{k}}=\left(1-a_{\mathrm{k}}\right) I_{\mathrm{k}}
$$




\subsection{Total inorganic flux}

The rate of total inorganic waste production or flux (i.e. total respiration and excretion) equals the ingestion rate minus body mass growth rate and egestion rate for each element (Schreck \& Moyle, 1990; Sterner \& Elser, 2002). If an element is limiting, the individual is likely to consume other elements in excess in order to meet the target for that limiting element. In such cases, it is often assumed that the exceeding "residual" element will be subject to postabsorptive release via inorganic waste production (i.e. residual flux $F_{\text {rk }}$ ) to maintain body homeostasis (Anderson et al., 2005). When $\mathrm{N}$ or $\mathrm{P}$ are limiting, for example, a certain residual amount of $\mathrm{C}, \mathrm{Fr}_{\mathrm{C}}$ remains unutilised. However, if $\mathrm{C}$ is limiting instead of $\mathrm{N}$ or $\mathrm{P}$, excretion rates $F_{\mathrm{N}}$ and $F_{\mathrm{P}}$ will increase by an overhead residual flux $F_{\mathrm{rk}}$. In the example of $\mathrm{C}$ limitation, the residual flux $F_{\mathrm{rC}}$ would equal zero. We can thus quantify the total inorganic flux as follows:

$$
F_{\mathrm{k}}=F_{0 \mathrm{k}}+F_{\mathrm{rk}},
$$

where

$$
F_{\text {rk }}=I_{\mathrm{k}}-G_{\mathrm{k}}-F_{0 \mathrm{k}}-W_{\mathrm{k}} \text {. }
$$

\section{Application}

We validate our modelling approach using data from three reef fish species: the herbivore Zebrasoma scopas (family Acanthuridae), the omnivore Balistapus undulatus (family Balistidae), and the carnivore Epinephelus merra (family Serranidae). All parameters were quantified using empirical data augmented with information from the literature when needed (see supplementary methods, Appendix S1). An overview of all parameter estimates is provided in Appendix S2, Table 1.

We ran the model using R (R Core Team, 2019) and Stan (Stan Development Team, 2018). For an easy application of the presented framework, we developed the R package fishflux, which provides a set of user-friendly functions to simulate the model, extract the output vari- 
ables, and visualize the results (see Appendix S1). Parameter means and standard deviations are provided, and a Monte Carlo method is applied to randomly draw each parameter assuming normal distributions in each iteration. To account for co-variances among parameters, we used the Stan function multi_normal_rng(), which samples each parameter under consideration of the co-variance matrix. We included co-variances for body stoichiometry $\left(Q_{\mathrm{k}}\right)$, diet stoichiometry $\left(D_{\mathrm{k}}\right)$, length-weight parameters $(\varepsilon$ and $b)$, and metabolic parameters $(\alpha$ and $f_{0}$ ). These parameters were sampled from their log-transformed multinormal distribution then back-transformed to natural scale. All other parameters were sampled from truncated normal distributions, where the lower and upper bounds are the possible ranges of each respective parameter. For our case study, we used 5,000 iterations. If the standard deviation of a given parameter is unknown (e.g. $r$, reported on FishBase), the function automatically fills in the standard deviation with a very low value of $10^{-9}$ in order to keep the respective parameter approximately constant at each iteration of the simulation.

To compare the predictions of ingestion and excretion rates of our model framework with the case where only $\mathrm{C}$-limitation is considered, we simulated ingestion and excretion rates, based only on the minimal supply rate of C, thus where $I_{\mathrm{c}}$ equals $S_{\mathrm{c}}$. Excretion rates or total inorganic flux rates of $\mathrm{N}$ and $\mathrm{P}$ are then defined as follows:

$$
F_{\mathrm{N}}=S_{\mathrm{C}} \frac{D_{\mathrm{N}}}{D_{\mathrm{C}}}-G_{\mathrm{N}}-W_{\mathrm{N}},
$$

$$
F_{\mathrm{P}}=S_{\mathrm{C}} \frac{D_{\mathrm{P}}}{D_{\mathrm{C}}}-G_{\mathrm{P}}-W_{\mathrm{P}} .
$$

We compared the predicted excretion rates for $\mathrm{N}$ and $\mathrm{P}$ with our own independent database of experimental excretion rates. We collected individual fish using barrier nets, dip nets, cast nets, traps, clove oil, and hook and line across different reef habitats around Moorea, French Polynesia during austral winter of 2016 and $2017(n=128)$. We aimed to collect individuals across the size spectrum present in each species. We immediately transported individuals back to shore in an aerated cooler for excretion experiments (see Appendix S1). Excretion rates were measured within a maximum of 3 hours after capture. The capture and handling of fishes 
for this project were approved in a protocol from the University of California Santa Barbara's Institutional Animal Care and Use Committee (IACUC \#915 2016-2019).

Finally, to illustrate the effect of diet stoichiometry, we simulated the model with varying $\%$ of $\mathrm{N}$ and $\mathrm{P}$. For this simulation, we used the parameters of $Z$. scopas and ran the simulation for an individual of $10 \mathrm{~cm}$. We kept $D_{\mathrm{C}}$ constant at $6 \%$. The values of $D_{\mathrm{N}}$ and $D_{\mathrm{P}}$ varied around the elemental ratio of $S_{\mathrm{k}}$. Color palettes were used from the R package fishualize (Schiettekatte, Brandl, \& Casey, 2019).

\section{Results}

The application of the developed modeling framework reveals distinct elemental limitations across the three species at different lengths (Fig. 2). Z. scopas is limited by either $\mathrm{N}$ or $\mathrm{P}$ over its full size range, with $\mathrm{P}$ being the limiting element early in its ontogeny and $\mathrm{N}$ becoming the limiting element after reaching approximately $7 \mathrm{~cm}$ TL. While $B$. undulatus and E. merra are also limited by $\mathrm{P}$ at an early life stage, they are predominantly limited by $\mathrm{C}$ upon maturation. 


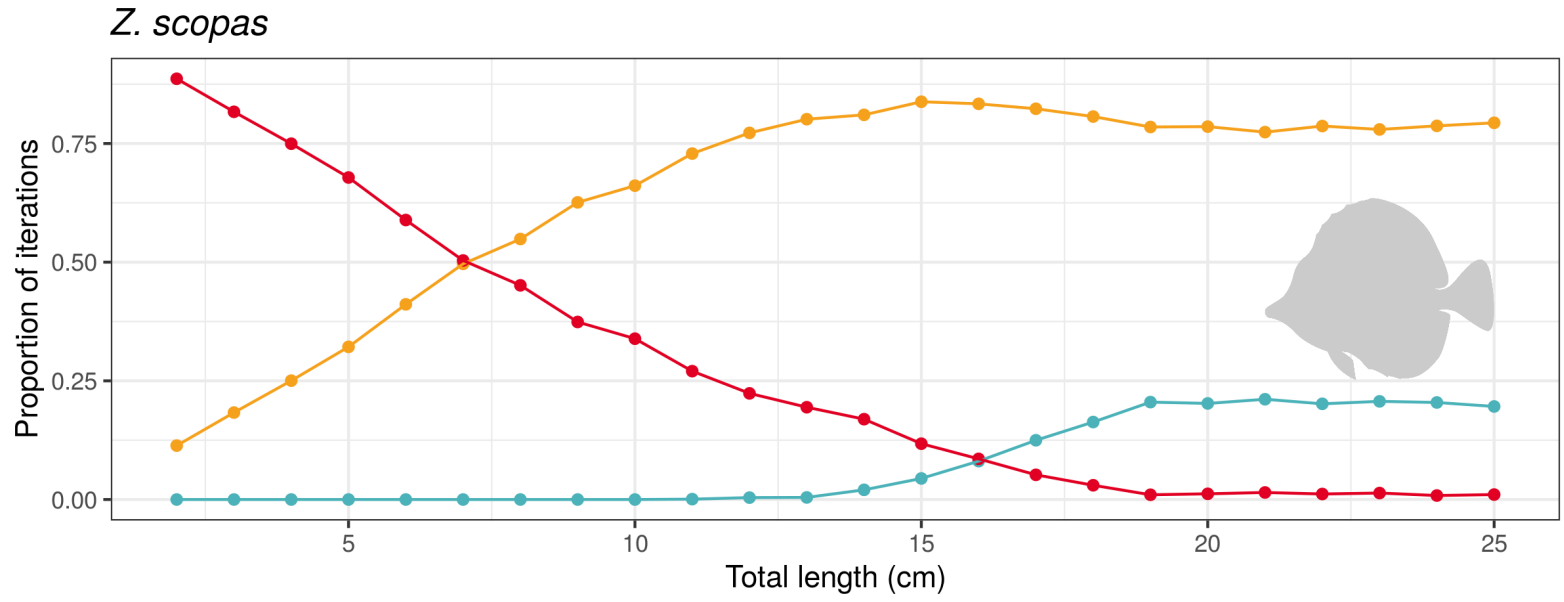

B. undulatus

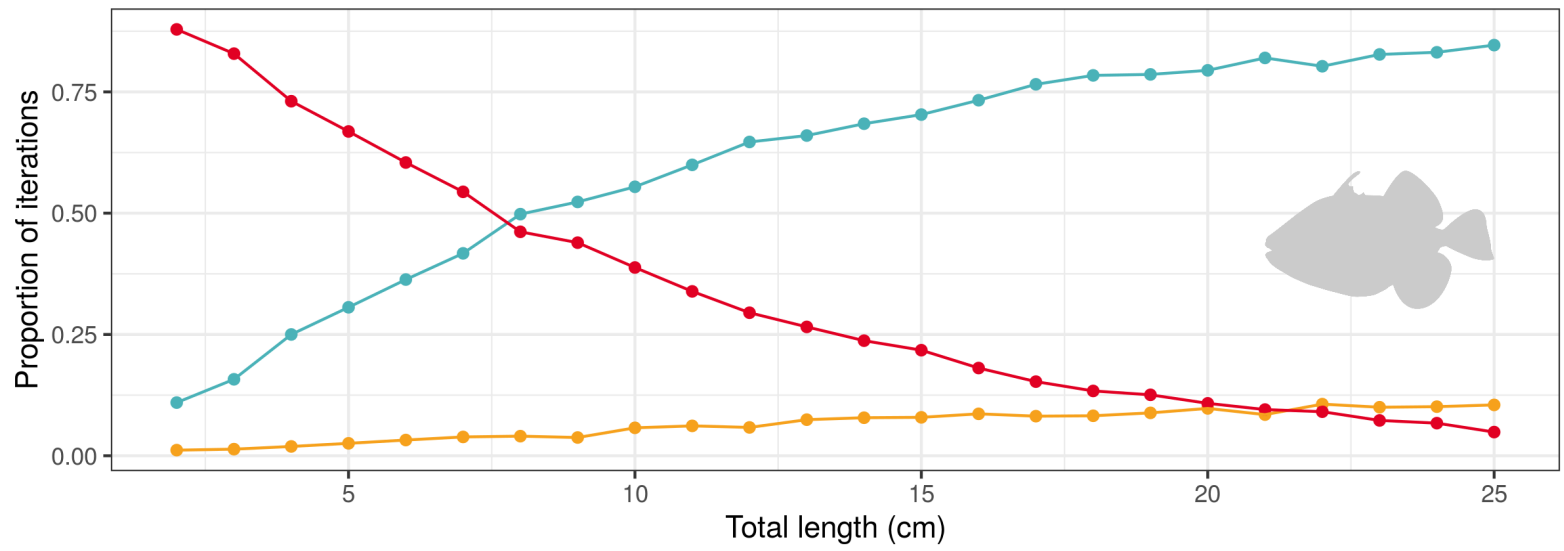

E. merra

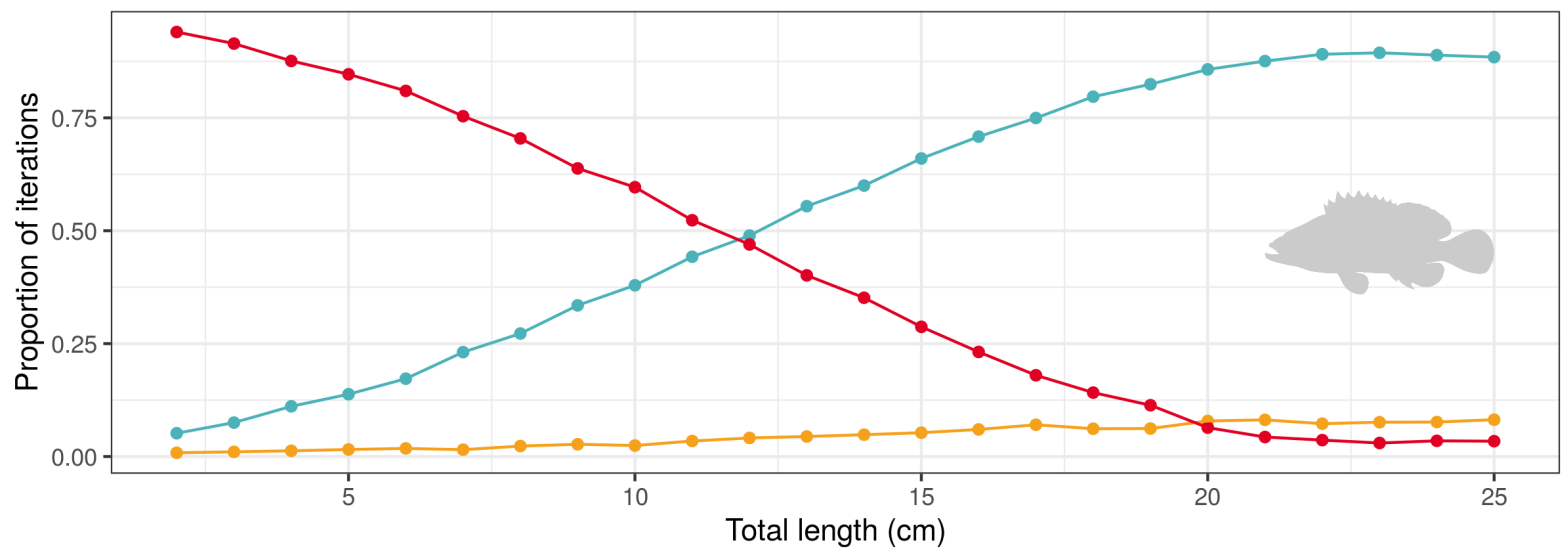

Limiting element $\rightarrow c \rightarrow n \rightarrow p$

Figure 2. Proportion of the simulation iterations that determine $\mathrm{C}, \mathrm{N}$ and $\mathrm{P}$ as the limiting element for Zebrasoma scopas, Balistapus undulatus, and Epinephelus merra. 
Our approach demonstrates that defining the limiting element can be critical to predict a species' ingestion rate, which affects all downstream calculations in the model (e.g. excretion rates of $\mathrm{N}$ and $\mathrm{P}$ ) compared to models only considering $\mathrm{C}$ limitation (Fig. 3). Specifically, assuming $\mathrm{C}$ limitation in $Z$. scopas results in a severe underestimation of ingestion and excretion rates (Fig. 3, A, B and C). In the omnivore B. undulatus and the carnivore $E$. merra, the limiting element has less bearing on ingestion rates. Still, without incorporation of $\mathrm{P}$ limitation, model predictions may result in negative excretion rates of $\mathrm{P}$ for growing individuals of $B$. undulatus and E. merra. In the case of E. merra, C-only models predict negative $\mathrm{P}$ excretion rates for more than half of the simulations under a total length of $10 \mathrm{~cm}$ (Fig.3, I). Thus, our framework reveals that nutrient limitations and their consequences for ingestion rate estimations are highly specific to the three study species and their ontogenetic stage. 

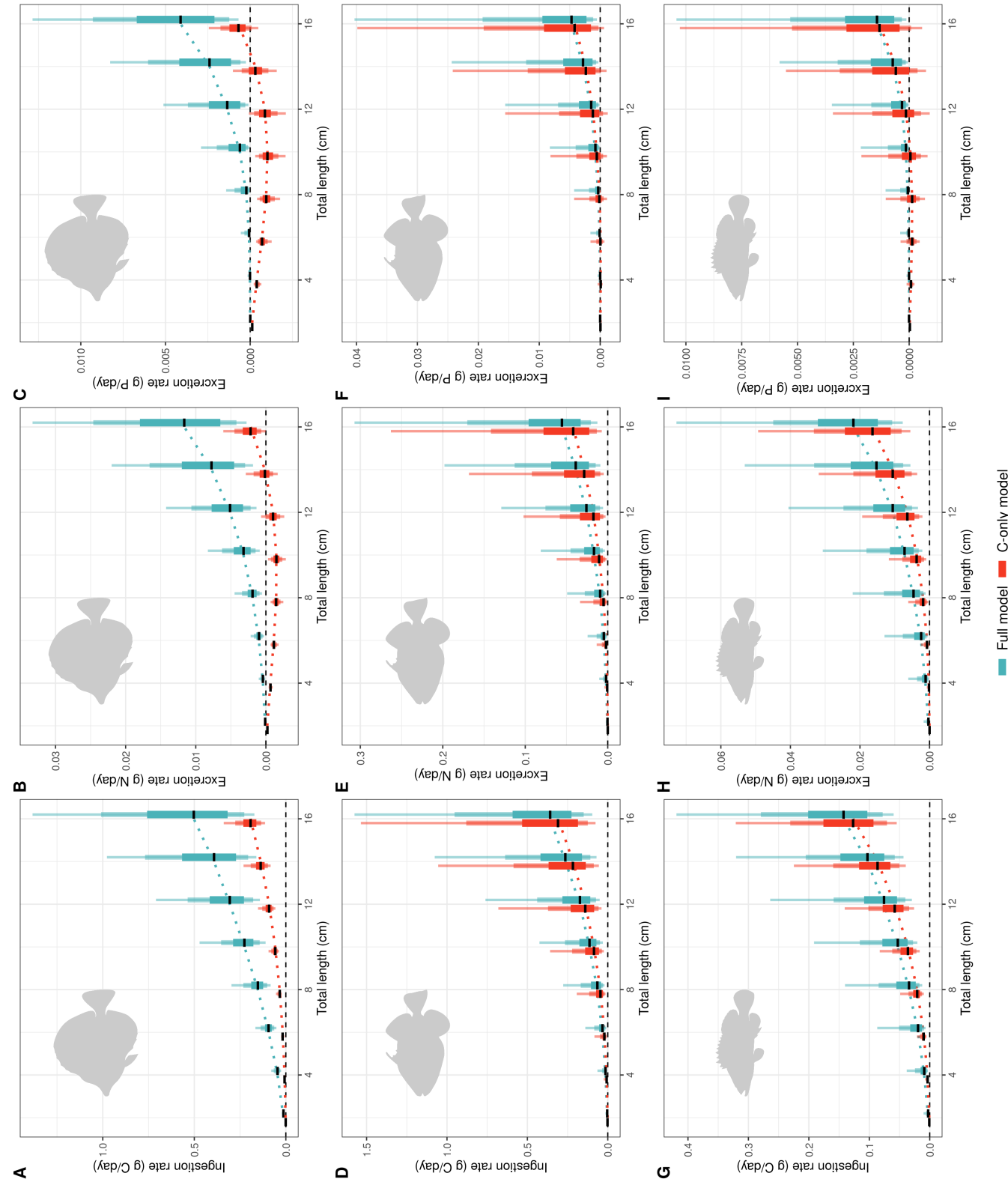

Figure 3. Predicted daily ingestion of carbon and excretion rates for the full model, considering nutrient limitation and for a model, only taking into account C-limitation. Horizontal lines show the median values and $95 \%, 80 \%$, and $50 \%$ confidence intervals are illustrated respectively in vertical lines. A. C ingestion rates of Z. scopas, B. N excretion rates of $Z$. scopas, A. P excretion rates of $Z$. scopas, A. C ingestion rates of B. undulatus, A. $\mathrm{N}$ excretion rates of $B$. undulatus, A. P excretion rates of B. undulatus, A. C ingestion rates of E. merra, A. N excretion rates of E. merra, A. P excretion rates of E. merra. 
Our model predicts ingestion rates for Z. scopas, B. undulatus and E. merra at $15 \mathrm{~cm}$ TL to be $28.2(11.7-68.4), 12.9(3.7-56.7), 14.1(5.5-40.1)$, respectively (in mg dry weight per $g$ wet weight of fish per day, median and 95\% confidence interval (C.I.)) (see Appendix S2, Table 2). Comparing our predicted excretion rates with empirical data on excretion rates shows that our model adequately predicts excretion rates with almost all experimental data falling inside the predicted $95 \%$ confidence interval (Fig. 4). For N excretion, 100\%, 97\% and 94\% of the experimental excretion rates are captured by our predictions for Z. scopas, B. undulatus and $E$. merra, respectively. For P excretion, we adequately predict $93 \%, 94 \%$, and $90 \%$ of the experimental excretion rates for the three species, respectively. Predictions for E. merra are slightly overestimated compared to experimental excretion rates. Groupers feed infrequently, and their stomachs were often found empty, which may have impacted the measured excretion rates. 

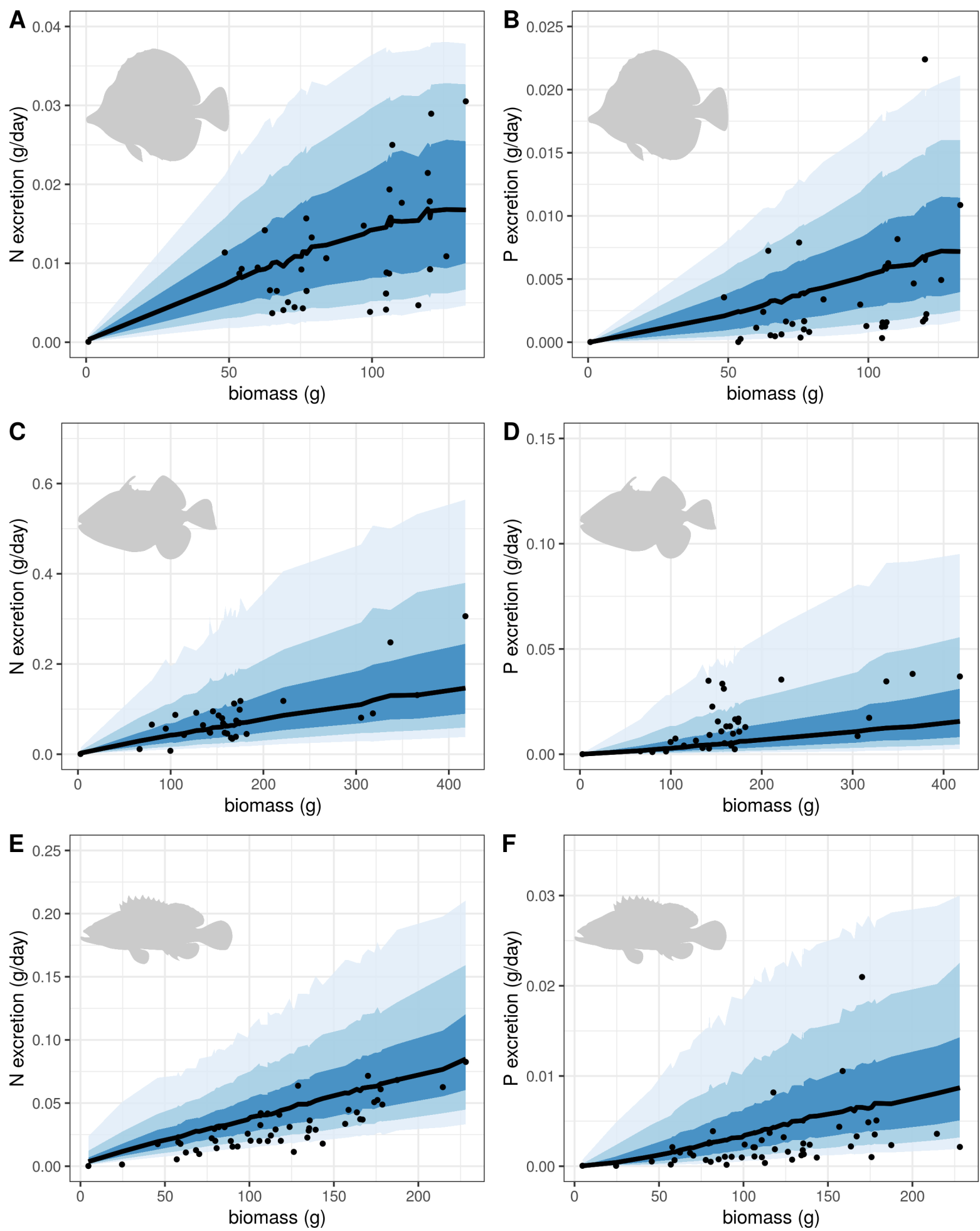

Figure 4. Predicted excretion rates for each species of both $\mathrm{N}$ and $\mathrm{P}$. The $50 \%, 80 \%$ and 95\% confidence intervals are presented around the median. Points show the experimental excretion rates, obtained from an independent database. A. $\mathrm{N}$ excretion rates of $Z$. scopas, B. P excretion rates of $Z$. scopas, C. $\mathrm{N}$ excretion rates of B. undulatus, D. P excretion rates of B. undulatus, E. N excretion rates of E. merra, F. P excretion rates of E. merra. 
Predictions are substantially affected by variability in the stoichiometry of dietary sources. To illustrate how the diet stoichiometry affects limitations by different elements and ingestion and excretion rates, we simulated different scenarios by varying the diet percentages of $\mathrm{N}$ and $\mathrm{P}$ around the stoichiometry of the minimal supply rate of an individual of $Z$. scopas of $10 \mathrm{~cm}$ (Fig. 5). When diet stoichiometry differs from this ideal stoichiometry of the minimal supply rate, either $\mathrm{C}, \mathrm{N}$ or $\mathrm{P}$ is the limiting element, which in turn affects all downstream biological processes. For example, when the percent of $\mathrm{P}$ in the diet is low, $\mathrm{P}$ is the limiting element (Fig. 5, A). This leads to an increased ingestion rate (Fig. 5, B), a minimal excretion rate of $\mathrm{P}$ (Fig. 5, C), and a high excretion rate of $\mathrm{N}$ (Fig. 5, D). 

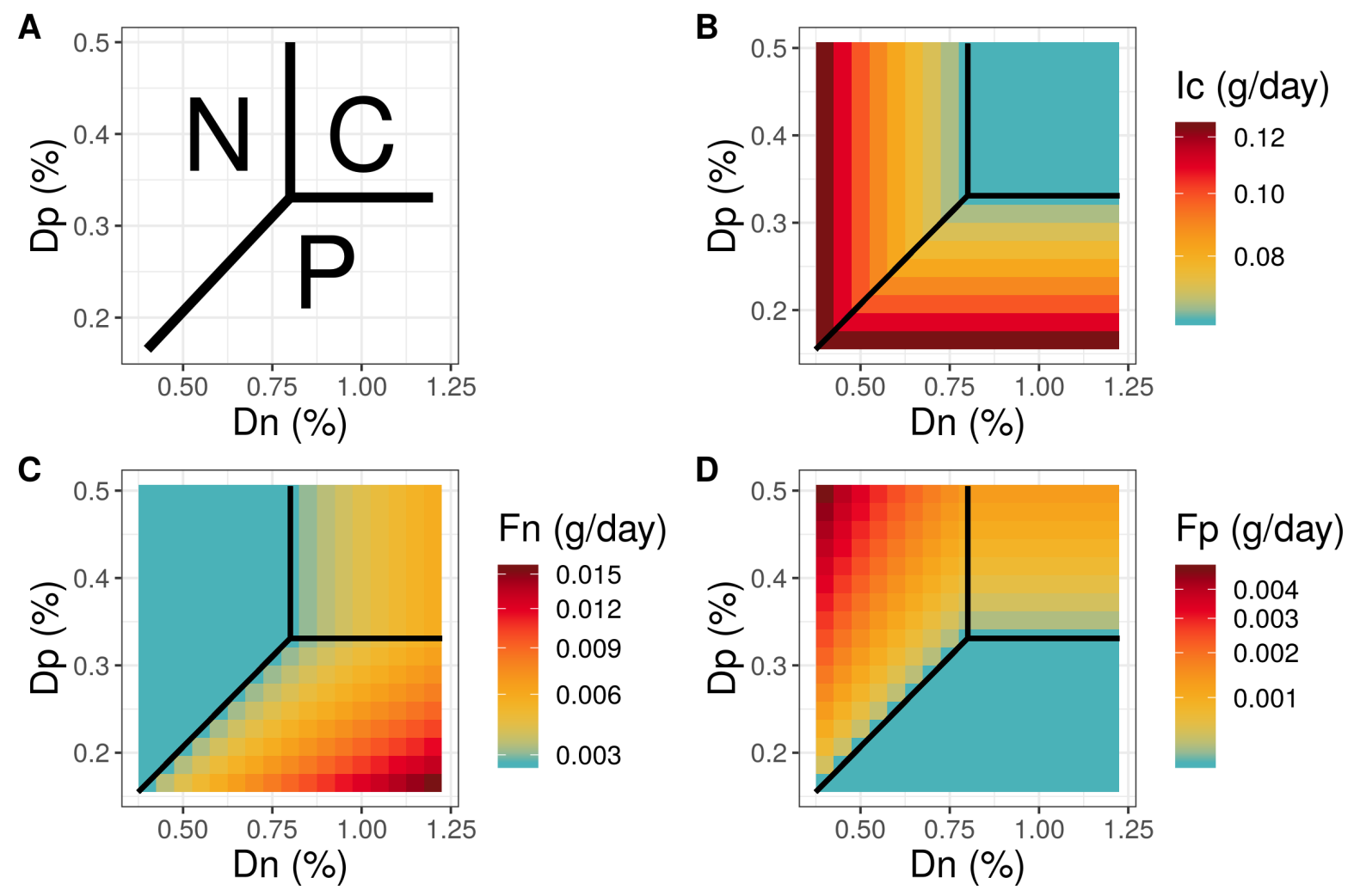

Figure 5. Model simulations with varying levels of $D_{\mathrm{N}}$ and $D_{\mathrm{P}} . D_{\mathrm{C}}$ is kept constant. Diet stoichiometry affects the limitation and the rates of multiple processes, such as the ingestion rate and excretion rates. A. The limiting element is indicated for varying levels of diet stoichiometry $\left(D_{\mathrm{N}}\right.$ and $\left.D_{\mathrm{P}}\right)$. Lines indicate where one limiting element switches to another. This is equivalent to the threshold elemental ratios, B. $I_{\mathrm{C}}$ or Ingestion rates of C (g/day), C. $F_{\mathrm{N}}$ or Total inorganic flux of $\mathrm{N}$ (g/day), D. $F_{\mathrm{P}}$ or Total inorganic flux of $\mathrm{P}$ (g/day). 


\section{Discussion}

Combining stoichiometry and bioenergetic modeling provides a framework to predict elemental fluxes in consumers and their contribution to key biogeochemical cycles. Here, we introduce a model that incorporates the nutrient requirements of fishes alongside their energetic needs to provide accurate predictions of their ingestion, respiration, excretion, and egestion rates. With our framework, we confirm the existence of nutrient limitation in fishes, specific to the trophic group and life stage, and its effect on multiple processes. We demonstrate the accuracy and applicability of the model to predict ingestion and excretion rates for three tropical reef fish species, while also reflecting the natural variability of these variables. Our framework provides an accurate tool to predict CNP fluxes in fishes across diverse trophic groups and gauge the role of fish consumers in ecosystems worldwide.

There is a growing consensus that many fishes are limited by nutrients (Benstead et al., 2014; El-Sabaawi et al., 2016; Hood2005; Moody et al., 2019). Yet, fish growth and maintenance are often assumed to be limited by energy (C) when applying coupled bioenergetic and stoichiometric models (Allgeier et al., 2013; Burkepile et al., 2013; Kraft, 1992; Schindler \& Eby, 1997). Our case study confirms that ingestion rates can indeed be determined by N or P limitation rather than $\mathrm{C}$ limitation, especially in species with nutrient-poor diets. This finding is expected given the elemental imbalance between the consumer's body and dietary CNP content; however, failing to account for nutrient limitation substantially skews predictions of ingestion rates. For example, assuming only energy limitation for a herbivorous adult Z. scopas would result in a greater than two-fold underestimation of its ingestion rate and consequently drastic underestimations of excretion and egestion rates. Given the high densities of species with nutrient-poor diets across a variety of ecosystems (e.g. herbivorous and detritivorous species; Williams \& Hatcher (1983); Takeuchi, Ochi, Kohda, Sinyinza, \& Hori (2010); Hood et al. (2005)), such underestimates may result in strong misconceptions about ecosystem-scale nutrients and energy fluxes. Our model framework provides a way to facilitate the direct incorporation of varying elemental limitation across species.

The developed model predicts ingestion through the integration of metabolic theory and ele- 
mental limitation, thus circumventing the difficult task of measuring ingestion rates in natural populations. Therefore, the first step of our framework focuses on quantifying the minimal supply rate for each element $\left(S_{\mathrm{k}}\right)$ and determining the limiting element. This includes both maintenance rates and element-specific growth rates based on the growth trajectory of natural populations. Then, by comparing the stoichiometry of these minimal supply rates with diet stoichiometry, we can determine the limiting element. This approach is inspired by the threshold elemental ratio (TER) theory, which predicts the ratio at which growth limitation switches from one element to another (Sterner \& Elser, 2002; Urabe \& Watanabe, 1992). In fishes, it is widely accepted to integrate metabolic rate into the calculation of TER's (Frost et al., 2006). We built on this work to account not only for maintenance requirements of $\mathrm{C}$, but also of $\mathrm{N}$ and P. Similar to the energy $(\mathrm{C})$ that is needed to sustain the metabolic rate of fishes in the wild, minimal $\mathrm{N}$ and $\mathrm{P}$ is needed to replace decaying cells and maintain body composition. The specific turnover rate of $\mathrm{P}\left(F_{0 \mathrm{Pz}}\right)$ is lower than the turnover rate of $\mathrm{N}\left(F_{0 \mathrm{Nz}}\right)$ because bone cells, which contain the majority of $\mathrm{P}$, degrade slowly compared to other cell types (Manolagas, 2000; Sterner \& Elser, 2002). Thus, including minimal requirements for all three elements lowers the TER of $\mathrm{C}$ and nutrients of fishes and increases the probability of detecting nutrient limitation.

The inclusion of nutrient limitation ensures that predicted excretion rates $\left(F_{\mathrm{P}}, F_{\mathrm{N}}\right)$ are always higher than zero. This is crucial since $\mathrm{N}$ and $\mathrm{P}$ will always be released at a minimal rate, even when they are limiting (Anderson et al., 2005; Mayor et al., 2011; Sterner \& Elser, 2002). Our approach reveals that all three study species are limited by P in their early life. By explicitly including minimal supply rates in our model, we move beyond simply detecting evidence for nutrient limitation (i.e. negative excretion rates; Hood et al, 2005) towards quantifying its effect on vital processes across species and ontogeny. Bone growth, for example, requires substantial amounts of $\mathrm{P}$ and is most rapid during early life-stages (Vanni, 2002), and evidence from freshwater ecosystems shows that P can limit fish growth (Benstead et al., 2014; Hood et al., 2005). The ontogenetic variation in elemental limitation presented herein confirms the importance of considering P-limitation for growth when predicting elemental fluxes in fishes.

Beyond the incorporation of nutrient limitation, our model framework provides a way to esti- 
mate uncertainty of predictions. Empirically-measured excretion rates can considerably vary for similarly sized individuals of the same species (Allgeier, Wenger, Rosemond, Schindler, \& Layman, 2015; Francis \& Côté, 2018; Whiles, Huryn, Taylor, \& Reeve, 2011). Yet, existing models that combine stoichiometry and bioenergetics do not account for this natural variability (e.g. Deslauriers et al., 2017), which hampers our ability to gauge the uncertainty of resulting estimates. With the use of MCMC iterations, the R package fishflux incorporates the distribution of parameters with their means and standard deviations, resulting in realistic credibility intervals of ingestion and excretion rates, although variability in model output does not necessarily reflect natural variability. The utility of this approach is clear when comparing our predictions to reported ingestion rates. For example, Z. scopas reportedly ingests 49 mg of dry mass per gram of wet fish weight (Polunin, Harmelin-Vivien, \& Galzin, 1995), a value centered within the predicted range of our model (11.7 - 68.4 at $15 \mathrm{~cm}$ TL). Similarly, the ingestion rate of juvenile coral trout, Plectropomus leopardus, a predatory species in the same family as E. merra (family Serranidae), ranges between 9 to $14 \mathrm{mg}$ of dry mass per gram of wet weight (Sun et al., 2014), which lies within the 95\% prediction for E. merra from our model $(5.5-40.1)$. Tracing the sensitivity of predictions to uncertainty in specific parameters enables the determination of the main sources of variability that may shift estimates among studies or species.

As all models, our approach relies on several simplifying assumptions. First, our model assumes that fishes maintain homeostasis (Sterner, 1990). Since fishes can have flexible body stoichiometry depending on dietary nutrient content (Benstead et al., 2014; Dalton et al., 2017), this assumption may impose biases when simulating effects of varying diet stoichiometry on elemental fluxes. Yet, empirically measures relationships between nutrient content of body and diet can easily be incorporated into our model simulations, thus ameliorating the effects of this simplification. Second, similar to most stoichiometric mass balance models, our framework is based on Liebig's minimal rule, which states that growth is strictly limited by the element in shortest supply relative to demand. However, there is emerging evidence that consumers may simultaneously be limited by more than one element (Sperfeld, MartinCreuzburg, \& Wacker, 2012). For example, P plays an essential role in fish energy uptake 
(Xie et al., 2011), and the incorporation of interactive co-limitation into stoichiometric models may further improve predictions of elemental fluxes. Finally, we assume that fishes follow a growth trajectory defined by the VBGC curve, and that there is enough food available in the natural environment to meet the growth requirements for each element. The VBGC is fitted on size-at-age data that are mostly acquired via annual otolith readings. In our model, we use this fitted growth function to estimate daily growth rates for each element through integration with length-weight relationships and body stoichiometry. This does not capture, for instance, seasonal variation of food availability. Other stoichiometric models mostly use gross growth efficiencies, or GGE's (i.e. growth/ingestion of the limiting element) (e.g. El-Sabaawi et al., 2016; Frost et al., 2006; Guariento et al., 2018; McManamay, Webster, Valett, \& Dolloff, 2011; Moody et al., 2019). However, consumer GGE's vary widely, and specific values are poorly understood (McManamay et al., 2011). Furthermore, even if element-specific GGE's are quantified, they may not reflect growth observed in natural populations. Therefore, we suggest that the use of otolith-based growth quantification provides a reasonable alternative to model elemental fluxes of natural fish populations.

Beyond model assumptions, the accuracy of our model naturally relies on the accuracy of each parameter estimate. Yet, parameters are often difficult to obtain. We sought to balance the accuracy of predictions and ease of application. Parameters involving growth, length-weight relationships, metabolism, and stoichiometry are increasingly accessible for many species due to predictive modeling and open-access databases (e.g. Froese, Thorson, \& Reyes, 2014; Barneche et al., 2014; Froese \& Pauly, 2018; Killen et al., 2016; Morais \& Bellwood, 2018; Vanni et al., 2017). Yet, there are a number of parameters that are still sparsely quantified and may limit the applicability of our framework. In particular, data on diet stoichiometry and assimilation efficiencies are rare. In our case study, we used assimilation efficiency constants for $\mathrm{C}, \mathrm{N}$ and $\mathrm{P}$, that are predominantly based on predatory fishes. In reality, assimilation efficiencies can vary substantially, and, in particular, assimilation efficiency of phosphorus is likely correlated with diet quality (Czamanski et al., 2011). Further, N- and P-specific turnover rates are newly introduced parameters and therefore poorly known. As these parameters depend on the cell turnover rates of $\mathrm{N}$ - and P-rich tissues (e.g. bone for P), we suggest that 
these parameters may be applicable across species. Nevertheless, further research is needed to gain further insight. While variation in these parameters can impact the model output via the limiting element and ingestion rate, ongoing compilations of databases of poorly known parameters will improve the application of the proposed modeling framework.

In addition, we quantified the activity scope (i.e. field metabolic rate) as the average of maximum metabolic rates (MMR) and standard metabolic rates (SMR) divided by the SMR, assuming that a fish reaches values close to MMR when undertaking activities in the wild (Murchie, Cooke, Danylchuk, \& Suski, 2011). In reality, activity scope may vary depending on life history traits and behavior (Killen, Norin, \& Halsey, 2017), and field metabolic rates can be elevated with the presence of predators, which in turn can affect nutrient cycling (Dalton, Tracy, Hairston, \& Flecker, 2018; Guariento et al., 2018). Recent advances, such as bio-telemetry (Norin \& Clark, 2016) or otolith chemistry (Chung, Trueman, Godiksen, Holmstrup, \& Grønkjær, 2019) may improve estimates of field metabolic rates. Similarly, specific dynamic action (SDA), which is the metabolic rate needed to assimilate food (Hou et al., 2008) depends on the quality and quantity of food (McCue, 2006) and may thus influence ingestion rates, but it is poorly known across most species. Finally, reproduction is not yet incorporated into the model because data on both gonad stoichiometry and reproductive growth is rare. This may underestimate energy and nutrient investment of fishes, thus skewing model predictions. Nonetheless, as new data on reproductive growth, activity scope, or SDA become available, these elements can be incorporated in the future.

Despite these limitations, our framework provides new avenues for addressing pressing questions in ecology. Data on the daily actions of fishes are difficult to obtain due to the challenges of conducting research in aquatic environments. Novel techniques such as fish gut content DNA metabarcoding (Casey et al., 2019) or compound-specific stable isotope analyses (Hopkins \& Ferguson, 2012) permit improved insights into species-specific ingestion of prey resources. However, no current empirical technique can estimate rates of food ingestion via these linkages across a broad range of species. Combining our model with emerging techniques to quantify species-specific resource use can help us to address long standing questions. How much prey do top predators consume daily? How do rates of algal consumption 
differ among herbivorous species? How much production by lower trophic levels is needed to fuel the growth of predatory fisheries species? By providing a tool to answer these questions, our model empowers fundamental and applied researchers to tackle some of the most outstanding questions in fish ecology.

Beyond single species and their pairwise interactions, our model provides means to examine community- and ecosystem-scale dynamics. Specifically, based on simple census data of fish communities, our model can help decompose system-wide fluxes (cf. Burkepile et al., 2013; Allgeier et al., 2014; Francis \& Côté, 2018). This is particularly important for open ecosystems in which the dominant sources of energy and nutrients are unclear or variable. For example, on coral reefs, debates persist on the importance of external (i.e. pelagic) subsidies versus internal nutrient cycling (e.g. Brandl, Tornabene, et al., 2019; Morais \& Bellwood, 2019). Our model can help estimate how much pelagic or benthic prey is consumed by reef fishes and how these resources are propagated through food webs, which enables researchers to quantify reef functioning (Brandl, Rasher, et al., 2019). Thus, merging what is eaten (i.e. food web assembly) with how much is eaten (i.e. realistic consumption rates as provided by our model) can significantly augment our understanding of ecosystem functioning, especially in systems where fishes are the dominant consumers.

Finally, given the heavy exploitation of fish communities for global human consumption, our model offers a tool for understanding and predicting the effect of human-driven changes on ecosystem functioning. Yearly, more than 100 million tons of fishes are caught in marine systems worldwide (Cashion et al., 2018), imposing an unparalleled top-down stressor on global fish communities, which erodes biomass and alters the size and trophic structure of fish communities (Essington, Beaudreau, \& Wiedenmann, 2006; Pauly, Christensen, Dalsgaard, Froese, \& Torres, 1998). As exemplified here, elemental fluxes are influenced by diet and life stage. Thus, our model provides a tool to estimate the impact of size and trophic structure shifts on elemental cycling. In addition, increasing temperatures resulting from climate change can affect primary production in the world's oceans, thus imposing a bottom-up effect on fish communities (Lotze et al., 2019), which are likewise affected by rising temperatures (Pinsky, Eikeset, McCauley, Payne, \& Sunday, 2019). Temperature is known to affect mul- 
tiple parameters in this model, such as metabolic rate and growth rate (Morais2018; Killen et al., 2016), which enables assessment of the impact of temperature on elemental fluxes. Given human-driven alterations in both primary production through climate change and fish community structure through extensive fishing, it is urgent to understand how these changes may impact biogeochemical fluxes. Our model and its implementation provide a path toward rising to this challenge.

\section{Data accessibility}

All data and code to reproduce figures will be available online on GitHub https://github.com/nschiett/.

The full model code is available on GitHub through the R package fishflux: https:/github.com/nschiett/fis 


\section{References}

Allgeier, J. E., Layman, C. A., Mumby, P. J., \& Rosemond, A. D. (2014). Consistent nutrient storage and supply mediated by diverse fish communities in coral reef ecosystems. Global Change Biology, 20(8), 2459-2472. doi: 10.1111/gcb.12566

Allgeier, J. E., Wenger, S. J., Rosemond, A. D., Schindler, D. E., \& Layman, C. A. (2015).

Metabolic theory and taxonomic identity predict nutrient recycling in a diverse food web. Proceedings of the National Academy of Sciences, 112(20), E2640-E2647. doi: $10.1073 /$ pnas. 1420819112

Allgeier, J. E., Yeager, L. A., \& Layman, C. A. (2013). Consumers regulate nutrient limitation regimes and primary production in seagrass ecosystems. Ecology, 94(2), 521-529. doi: $10.1890 / 12-1122.1$

Anderson, T. R., Hessen, D. O., Elser, J. J., \& Urabe, J. (2005). Metabolic stoichiometry and the fate of excess Carbon and Nutrients in Consumers. The American Naturalist, 165(1), 115. doi: $10.1086 / 426598$

Barneche, D. R., \& Allen, A. P. (2018). The energetics of fish growth and how it constrains food-web trophic structure. Ecology Letters, 21(6), 836-844. doi: 10.1111/ele.12947

Barneche, D. R., Kulbicki, M., Floeter, S. R., Friedlander, A. M., Maina, J., \& Allen, A. P. (2014). Scaling metabolism from individuals to reef-fish communities at broad spatial scales. Ecology Letters, 17(9), 1067-1076. doi: 10.1111/ele.12309

Benstead, J. P., Hood, J. M., Whelan, N. V., Kendrick, M. R., Nelson, D., Hanninen, A. F., \& Demi, L. M. (2014). Coupling of dietary phosphorus and growth across diverse fish taxa: A meta-analysis of experimental aquaculture studies. Ecology, 95(10), 2768-2777. doi: $10.1890 / 13-1859.1$

Bertalanffy, L. von. (1957). Quantitative laws in metabolism and growth. The Quarterly Review of Biology, 32, 217-231. doi: 10.1086/401873

Brandl, Rasher, D. B., Côté, I. M., Casey, J. M., Darling, E. S., Lefcheck, J. S., \& Duffy, J. E. (2019). Coral reef ecosystem functioning: Eight core processes and the role of biodiversity. 
Frontiers in Ecology and the Environment, 17(8), 445-454. doi: 10.1002/fee.2088

Brandl, Tornabene, L., Goatley, C. H. R., Casey, J. M., Morais, R. A., Côté, I. M., ... Bellwood, D. R. (2019). Demographic dynamics of the smallest marine vertebrates fuel coral reef ecosystem functioning. Science, 364(6446), 1189-1192. doi: 10.1126/science.aav3384

Brown, J. H., Gillooly, J. F., Allen, A. P., Savage, V. M., \& West, G. B. (2004). Toward a metabolic theory of ecology. Ecology, 85(7), 1771-1789. doi: Doi 10.1890/03-9000

Burkepile, D. E., Allgeier, J. E., Shantz, A. A., Pritchard, C. E., Lemoine, N. P., Bhatti, L. H., \& Layman, C. A. (2013). Nutrient supply from fishes facilitates macroalgae and suppresses corals in a Caribbean coral reef ecosystem. Scientific Reports, 3(1), 1493. doi: 10.1038/srep01493

Capps, K. A., \& Flecker, A. S. (2013). Invasive Fishes Generate Biogeochemical Hotspots in a Nutrient-Limited System. PLoS ONE, 8(1), e54093. doi: 10.1371/journal.pone.0054093

Casey, J. M., Meyer, C. P., Morat, F., Brandl, S. J., Planes, S., \& Parravicini, V. (2019).

Reconstructing hyperdiverse food webs: gut content metabarcoding as a tool to disentangle trophic interactions on coral reefs. Methods in Ecology and Evolution, 00, 1-14. doi: 10.1111/2041-210X.13206

Cashion, T., Al-Abdulrazzak, D., Belhabib, D., Derrick, B., Divovich, E., Moutopoulos, D. K., ... Pauly, D. (2018). Reconstructing global marine fishing gear use: Catches and landed values by gear type and sector. Fisheries Research, 206, 57-64. doi:

10.1016/j.fishres.2018.04.010

Chung, M.-T., Trueman, C. N., Godiksen, J. A., Holmstrup, M. E., \& Grønkjær, P. (2019). Field metabolic rates of teleost fishes are recorded in otolith carbonate. Communications Biology, 2(1), 24. doi: 10.1038/s42003-018-0266-5

Czamanski, M., Nugraha, A., Pondaven, P., Lasbleiz, M., Masson, A., Caroff, N., ... Tréguer, P. (2011). Carbon, nitrogen and phosphorus elemental stoichiometry in aquacultured and wild-caught fish and consequences for pelagic nutrient dynamics. Marine Biology, 158(12), 2847-2862. doi: 10.1007/s00227-011-1783-7 
Dalton, C. M., El-Sabaawi, R. W., Honeyfield, D. C., Auer, S. K., Reznick, D. N., \& Flecker, A. S. (2017). The influence of dietary and whole-body nutrient content on the excretion of a vertebrate consumer. PLoS ONE, 12(1), e0187931. doi: 10.1371/journal.pone.0187931

Dalton, C. M., Tracy, K. E., Hairston, N. G., \& Flecker, A. S. (2018). Fasting or fear: disentangling the roles of predation risk and food deprivation in the nitrogen metabolism of consumers. Ecology, 99(3), 681-689. doi: 10.1002/ecy.2132

Deslauriers, D., Chipps, S. R., Breck, J. E., Rice, J. A., \& Madenjian, C. P. (2017). Fish Bioenergetics 4.0: An R-Based Modeling Application. Fisheries, 42(11), 586-596. doi: $10.1080 / 03632415.2017 .1377558$

El-Sabaawi, R. W., Warbanski, M. L., Rudman, S. M., Hovel, R., \& Matthews, B. (2016). Investment in boney defensive traits alters organismal stoichiometry and excretion in fish. Oecologia, 181(4), 1209-1220. doi: 10.1007/s00442-016-3599-0

Essington, T. E., Beaudreau, A. H., \& Wiedenmann, J. (2006). Fishing through marine food webs. Proceedings of the National Academy of Sciences of the United States of America, 103(9), 3171-3175. doi: 10.1073/pnas.0510964103

Francis, F. T., \& Côté, I. M. (2018). Fish movement drives spatial and temporal patterns of nutrient provisioning on coral reef patches. Ecosphere, 9(5), e02225. doi: 10.1002/ecs2.2225 Froese, R., \& Pauly, D. (2018). FishBase. World Wide Web Electronic Publication. Froese, R., Thorson, J. T., \& Reyes, R. B. (2014). A Bayesian approach for estimating length-weight relationships in fishes. Journal of Applied Ichthyology, 30(1), 78-85. doi: 10.1111/jai.12299

Frost, P. C., Benstead, J. P., Cross, W. F., Hillebrand, H., Larson, J. H., Xenopoulos, M. A., \& Yoshida, T. (2006). Threshold elemental ratios of carbon and phosphorus in aquatic consumers. Ecology Letters, 9(7), 774-779. doi: 10.1111/j.1461-0248.2006.00919.x

Graham, N. A., McClanahan, T. R., MacNeil, M. A., Wilson, S. K., Cinner, J. E., Huchery, C., \& Holmes, T. H. (2017). Human Disruption of Coral Reef Trophic Structure. Current Biology, 27(2), 231-236. doi: 10.1016/j.cub.2016.10.062 
Guariento, R. D., Luttbeg, B., Carneiro, L. S., \& Caliman, A. (2018). Prey adaptive behaviour under predation risk modify stoichiometry predictions of predator-induced stress paradigms. Functional Ecology, 32(6), 1631-1643. doi: 10.1111/1365-2435.13089

Hanson, P., Johnson, T. B., Schindler, D. E., \& Kitchell, J. F. (1997). Fish Bioenergetics 3.0. Hessen, D. O., Ågren, G. I., Anderson, T. R., Elser, J. J., \& De Ruiter, P. C. (2004). Carbon sequestration in ecosystems: The role of stoichiometry. Ecology, 85(5), 1179-1192. doi: $10.1890 / 02-0251$

Hood, J. M., Vanni, M. J., \& Flecker, A. S. (2005). Nutrient recycling by two phosphorus-rich grazing catfish: The potential for phosphorus-limitation of fish growth. Oecologia, 146(2), 247-257. doi: 10.1007/s00442-005-0202-5

Hopkins, J. B., \& Ferguson, J. M. (2012). Estimating the Diets of Animals Using Stable Isotopes and a Comprehensive Bayesian Mixing Model. PLoS ONE, 7(1), e28478. doi: 10.1371/journal.pone.0028478

Hou, C., Zuo, W., Moses, M. E., Woodruff, W. H., Brown, J. H., \& West, G. B. (2008). Energy Uptake and Allocation During Ontogeny. Science, 322(5902), 736-739. doi: $10.1126 /$ science. 1162302

Killen, S. S., Glazier, D. S., Rezende, E. L., Clark, T. D., Atkinson, D., Willener, A. S. T., \& Halsey, L. G. (2016). Ecological Influences and Morphological Correlates of Resting and Maximal Metabolic Rates across Teleost Fish Species. The American Naturalist, 187(5), 592606. doi: $10.1086 / 685893$

Killen, S. S., Norin, T., \& Halsey, L. G. (2017). Do method and species lifestyle affect measures of maximum metabolic rate in fishes? Journal of Fish Biology, 90(3), 1037-1046. doi: $10.1111 / \mathrm{jfb} .13195$

Kitchell, J. F., Koonce, J. F., Magnuson, J. J., O’Neill, R. V., Shugart, H. H., \& Booth, R. S. (1974). Model of fish biomass dynamics. Transactions of the American Fisheries Society, 103(4), 786-798. doi: 10.1577/1548-8659(1974)103<786:MOFBD>2.0.CO;2

Kooijman, S. (2010). Dynamic energy budget theory - summary of concepts of the 
third edition. Dynamic Energy Budget Theory for Metabolilc Organization, 64. doi:

\section{$10.1017 / \mathrm{CBO} 9780511565403$}

Kraft, C. (1992). Estimates of phosphorus and nitrogen cycling by fish using a bioenergetics approach. Canadian Journal of Fisheries and Aquatic Sciences, 49(12), 2596-2604. doi: $10.1139 / \mathrm{f} 92-287$

Lotze, H. K., Tittensor, D. P., Bryndum-Buchholz, A., Eddy, T. D., Cheung, W. W. L., Galbraith, E. D., ... Worm, B. (2019). Global ensemble projections reveal trophic amplification of ocean biomass declines with climate change. Proceedings of the National Academy of Sciences, 116(26), 12907-12912. doi: 10.1073/PNAS.1900194116

Mackenzie, F. T., Ver, L. M., Sabine, C., Lane, M., \& Lerman, A. (1993). C, N, P, S Global Biogeochemical Cycles and Modeling of Global Change. In Interactions of $c, n, p$ and $s$ biogeochemical cycles and global change (pp. 1-61). doi: 10.1007/978-3-642-76064-8_1

Manolagas, S. C. (2000). Birth and Death of Bone Cells: Basic Regulatory Mechanisms and Implications for the Pathogenesis and Treatment of Osteoporosis 1. Endocrine Reviews, 21(2), 115-137. doi: 10.1210/edrv.21.2.0395

Mayor, D. J., Cook, K., Thornton, B., Walsham, P., Witte, U. F., Zuur, A. F., \& Anderson, T. R. (2011). Absorption efficiencies and basal turnover of C, $\mathrm{N}$ and fatty acids in a marine Calanoid copepod. Functional Ecology, 144(4), 381-394. doi: 10.1111/j.13652435.2010.01791.x

McCue, M. D. (2006). Specific dynamic action: A century of investigation. Comparative Biochemistry and Physiology - A Molecular and Integrative Physiology, 144(4), 381-394. doi: 10.1016/j.cbpa.2006.03.011

McIntyre, P. B., Flecker, A. S., Vanni, M. J., Hood, J. M., Taylor, B. W., \& Thomas, S. A. (2008). Fish distributions and nutrient cycling in streams: can fish create biogeochemical hotspots. Ecology, 89(8), 2335-2346. doi: 10.1890/07-1552.1

McManamay, R. A., Webster, J. R., Valett, H. M., \& Dolloff, C. A. (2011). Does diet influence consumer nutrient cycling? Macroinvertebrate and fish excretion in streams. Journal of the North American Benthological Society, 30(1), 84-102. doi: 10.1899/09-152.1 
Moody, E. K., Carson, E. W., Corman, J. R., Espinosa-Pérez, H., Ramos, J., Sabo, J. L., \& Elser, J. J. (2018). Consumption explains intraspecific variation in nutrient recycling stoichiometry in a desert fish. Ecology, 99(7), 1552-1561. doi: 10.1002/ecy.2372

Moody, E. K., Lujan, N. K., Roach, K. A., \& Winemiller, K. O. (2019). Threshold elemental ratios and the temperature dependence of herbivory in fishes. Functional Ecology, 33(5), 913923. doi: 10.1111/1365-2435.13301

Morais, R. A., \& Bellwood, D. R. (2018). Global drivers of reef fish growth. Fish and Fisheries, 19(5), 874-889. doi: 10.1111/faf.12297

Morais, R. A., \& Bellwood, D. R. (2019). Pelagic Subsidies Underpin Fish Productivity on a Degraded Coral Reef. Current Biology, 29(9), 1521-1527.e6. doi: 10.1016/J.CUB.2019.03.044

Murchie, K. J., Cooke, S. J., Danylchuk, A. J., \& Suski, C. D. (2011). Estimates of field activity and metabolic rates of bonefish (Albula vulpes) in coastal marine habitats using acoustic tri-axial accelerometer transmitters and intermittent-flow respirometry. Journal of Experimental Marine Biology and Ecology, 396(2), 147-155. doi: 10.1016/j.jembe.2010.10.019

Norin, T., \& Clark, T. D. (2016). Measurement and relevance of maximum metabolic rate in fishes. Journal of Fish Biology, 88(1), 122-151. doi: 10.1111/jfb.12796

Odum, H. T., \& Odum, E. P. (1955). Trophic Structure and Productivity of a Windward Coral Reef Community on Eniwetok Atoll. Ecological Monographs, 25(3), 291-320. doi: $10.2307 / 1943285$

Pauly, D., Christensen, V., Dalsgaard, J., Froese, R., \& Torres, F. (1998). Fishing down marine food webs. Science, 279(5352), 860-863. doi: 10.1126/science.279.5352.860

Pinsky, M. L., Eikeset, A. M., McCauley, D. J., Payne, J. L., \& Sunday, J. M. (2019). Greater vulnerability to warming of marine versus terrestrial ectotherms. Nature, 569(7754), 108-111. doi: $10.1038 / \mathrm{s} 41586-019-1132-4$

Polunin, N. V., Harmelin-Vivien, M., \& Galzin, R. (1995). Contrasts in algal food processing among five herbivorous coral $\square$ reef fishes. Journal of Fish Biology, 47(3), 455-465. doi: 
10.1111/j.1095-8649.1995.tb01914.x

R Core Team. (2019). $R$ : A language and environment for statistical computing. Retrieved from https://www.R-project.org/

Schiettekatte, N., Brandl, S., \& Casey, J. (2019). Fishualize: Color palettes based on fish species. Retrieved from https://github.com/nschiett/fishualize

Schindler, D. E., \& Eby, L. A. (1997). Stoichiometry of fishes and their prey: Implications for nutrient recycling. Ecology, 78(6), 1816-1831. doi: 10.1890/00129658(1997)078[1816:SOFATP]2.0.CO;2

Schreck, C. B., \& Moyle, P. B. (1990). Methods for Fish Biology (pp. 1-387).

Sperfeld, E., Martin-Creuzburg, D., \& Wacker, A. (2012). Multiple resource limitation theory applied to herbivorous consumers: Liebig's minimum rule vs. interactive co-limitation. Ecology Letters, 15(2), 142-150. doi: 10.1111/j.1461-0248.2011.01719.x

Stan Development Team. (2018). RStan: the $R$ interface to Stan. $R$ package version 2.17.3. doi: $10.3168 /$ jds.S0022-0302(63)89186-9

Sterner, R., \& Elser, J. (2002). Ecological Stoichiometry: The Biology of Elements from Molecules to the Biosphere (pp. 1-439). Retrieved from https://press.princeton.edu/ titles/7434.html

Sterner, R. W. (1990). The ratio of nitrogen to phosphorus resupplied by herbivores: zooplankton and the algal competitive arena. American Naturalist, 136(2), 209-229. doi: $10.1086 / 285092$

Sun, Z., Xia, S., Feng, S., Zhang, Z., Rahman, M. M., Rajkumar, M., \& Jiang, S. (2014). Effects of water temperature on survival, growth, digestive enzyme activities, and body composition of the leopard coral grouper Plectropomus leopardus. Fisheries Science, 81(1), 107112. doi: $10.1007 / \mathrm{s} 12562-014-0832-9$

Takeuchi, Y., Ochi, H., Kohda, M., Sinyinza, D., \& Hori, M. (2010). A 20-year census of a rocky littoral fish community in Lake Tanganyika. Ecology of Freshwater Fish, 19(2), 239248. doi: $10.1111 / \mathrm{j} .1600-0633.2010 .00408 . \mathrm{x}$ 
Urabe, J., \& Watanabe, Y. (1992). Possibility of N or P limitation for planktonic cladocerans: An experimental test. Limnology and Oceanography, 37(2), 244-251. doi:

10.4319/1o.1992.37.2.0244

Vanni, M. J. (2002). Nutrient Cycling by Animals in Freshwater Ecosystems. Annual Review of Ecology and Systematics, 33(1), 341-370. doi: 10.1146/annurev.ecolsys.33.010802.150519

Vanni, M. J., McIntyre, P. B., Allen, D., Arnott, D. L., Benstead, J. P., Berg, D. J., ... Zimmer, K. D. (2017). A global database of nitrogen and phosphorus excretion rates of aquatic animals. Ecology, 98, 1475. doi: 10.1002/ecy.1792

Welti, N., Striebel, M., Ulseth, A. J., Cross, W. F., DeVilbiss, S., Glibert, P. M., ... Hillebrand, H. (2017). Bridging food webs, ecosystem metabolism, and biogeochemistry using ecological stoichiometry theory. Frontiers in Microbiology, $8(\mathrm{JUL}), 1298$. doi: 10.3389/fmicb.2017.01298

Whiles, M. R., Huryn, A. D., Taylor, B. W., \& Reeve, J. D. (2011). Influence of handling stress and fasting on estimates of ammonium excretion by tadpoles and fish: recommendations for designing excretion experiments. Limnology and Oceanography: Methods, 7(1), 1-7. doi: 10.4319/lom.2009.7.1

Williams, D., \& Hatcher, A. (1983). Structure of Fish Communities on Outer Slopes of Inshore, Mid-Shelf and Outer Shelf Reefs of the Great Barrier Reef. Marine Ecology Progress Series, 10, 239-250. doi: 10.3354/meps010239

Xie, N. B., Feng, L., Liu, Y., Jiang, J., Jiang, W. D., Hu, K., ... Zhou, X. Q. (2011). Growth, body composition, intestinal enzyme activities and microflora of juvenile Jian carp (Cyprinus carpio var. Jian) fed graded levels of dietary phosphorus. Aquaculture Nutrition, 17, 645-656. doi: 10.1111/j.1365-2095.2011.00867.x 